\title{
Tax Seminar III on Double Tax Treaty Abuse, BEPS Developments (Action 6) and Selected Aspects on Article 7 OECD MC (Authorised OECD Approach)
}

\author{
Valentin Schneebeli, Chantelle Senden \& Andrzej \\ Stasio
}

\section{Introduction}

A tax seminar for students following the LL.M courses in International Taxation of Business Income and International Tax Planning and Transfer Pricing was held at the Faculty of Arts and Social Sciences of Maastricht University on 15 May, 2014. The objective of this seminar was to provide the students with additional information and insights on Double Tax Treaty Abuse and Article 7 OECD Model Tax Convention on Income and Capital (OECD MC) in preparation for their upcoming exam and, at the same time, give them a deeper understanding of the current Base Erosion and Profit Shifting (BEPS) developments.

Dr Marcel Schaper, assistant professor of law at Maastricht University, welcomed the speakers as well as the participating students and gave a brief introduction to the subject of the seminar. The seminar featured two presentations given by Mr Carlos Gutierrez and Mr Luis Nouel, both IBFD principal research associates.

\section{Double Tax Treaty Abuse, Beneficial Ownerships and BEPS Developments (Focus on Action 6)}

Mr Carlos Gutierrez presentation consisted of four parts: Treaty Shopping, Beneficial Ownership, Treaty and Anti Avoidance Rules and BEPS Action 6 proposals. 


\section{$2.1 \quad$ Treaty Shopping}

With treaty shopping some countries face annual losses in withholding taxes due to their treaties with the Netherlands. Especially South American countries e.g. Argentina, Brazil, Mexico and Venezuela face serious losses with regard to interest and dividend ${ }^{1}$. Also Kazakhstan is facing these losses resulting from concluded tax treaties with the Netherlands and in the case of Mongolia this development resulted in the fact that Mongolia has terminated the tax treaty with the Netherlands in 2012. However, a termination of the treaty is an "ultima ratio", since it creates more double taxation and is a starting point to renegotiate the treaty. A general interpretation of treaties without an anti-avoidance rule or limitation on benefits clauses, treaty shopping is not illegal. He pointed out, that the Dutch Sandwich is one way to avoid taxes and get treaty benefits, due to the lack of beneficial ownership clauses.

\subsection{Beneficial Ownership}

The limitation on benefit (LOB) clauses say that the person in the resident state must be the beneficial owner of the income, when receiving it. Only in this scenario he is entitled to treaty benefits. Nonetheless the definition of beneficial owner is not defined in the treaties and this leads to different interpretation according to $\mathrm{Mr}$ Carlos Gutierrez. The first consideration which has to be made is on which legal grounds the interpretation should take place. If there is no definition in domestic law then the context requires an interpretation of the term in a different way. The proposed interpretation would be based in good faith and in the context of the treaty and this would mean that an international interpretation has to be made.

The additional question if the legal owner or the economic owner is the determining criteria has been made visible on a court case. In the Prevost Case the Canadian tax authorities argued that the CA-NL tax treaty could not be applied as the Dutch entity is not the beneficial owner of the dividends. However the Court accepted the Dutch entity based on their definition that the beneficial owner is the person who received the dividends for his or her own use and enjoyment and assumes the risk and control of the dividends he received. The criteria

1 Detailled numbers in "Should the Netherlands Sign Tax Treaties with Developing Countries?" Report of SOMO, June 2013. 
possession, use, risk and control have been similarly applied in the Velcro case.

\subsection{Treaty and Anti-Avoidance Rules}

The anti-avoidance rules can be distinguished in specific domestic antiavoidance rules e.g. controlled foreign companies (CFC) rules, thin capitalization rules, anti-hybrid rules, anti-tax haven rules, anti-debt creation rules, anti-dual resident rules and exit taxes and general domestic anti-avoidance principles (GAARS) e.g. substance over form, sham transactions, business purpose test and the fraus legis/abuse of law concept.

The OECD suggests that the states should follow an approach including GAAR and in addition implicit anti-avoidance rules in the treaties that allow treaty benefits to be denied in cases of abuse. This anti-abuse rules in tax treaties are on the one hand a general anti-abuse clause and on the other hand specific anti-abuse rules against conduit companies e.g. the look through approach, exclusion approach and channel approach.

\subsection{BEPS Action 6 proposals}

Now with the financial crisis, countries are losing a lot of income. The G20 nations came up with an action plan as a new creation of rules introduced in the model in order to deal with this treaty abuse. Especially model tax provisions should be implemented in the OECD MC and not in the Commentary. A direct approach should need to be taken with LOB provisions and a general anti-abuse rule. Thereby there is already a conflict visible between the US which has already implemented strong LOB provisions and the UK which has extensive general-anti abuse rules and therefore both intend that their implementation would suffice.

\section{Attribution of Profits to Permanent Establishments}

Mr Luis Nouel presentation focused on the attribution of profits to permanent establishments (PEs) and consisted of three parts: general discussion of Article 7 OECD MC, the arm's length principle and the attribution of costs and expenses. 


\subsection{Article 7 of the OECD Model}

The main goal of Article 7 OECD MC is to allocate taxing rights between the resident country (country $\mathrm{R}$ ) of the enterprise and the source country (country S) of the PE. According to Article 7 OECD MC, country $\mathrm{R}$ may tax the profits of the $\mathrm{PE}$, but must provide double tax relief according to Article 23 OECD MC. At the same time, country S may tax the profit of the $P E$, but only if it is attributable to that $P E$. It is important to note that the OECD MC, or the particular bilateral treaty, does not explain how profits of the enterprise or the PE are to be calculated.

Different sources of interpretation of Article 7 OECD MC exist. The most recent sources are the new Article 7 and the Commentary to Article 7 from July 2010 and the 2010 Report on the attribution of profits to a PE. However, most bilateral tax treaties still use the old Article 7 and the revised Commentary to Article 7 from July 2008 and the 2008 Report on attribution of profits to a PE. Whereas, the OECD MC and its Commentary remains the main source of interpretation, the UN Model is also gaining in importance.

\subsection{The Arm's Length Principle}

Mr Nouel continued his presentation with a discussion of the arm's length principle, which is the basis for Article 7 OECD MC. This principle states that profits should be attributed to the $P E$, as a separate enterprise, under the same or similar conditions, performing the same or similar activities, independently from the enterprise.

In allocation of profits to the PE, the OECD uses the Authorized OECD Approach (AOA). The AOA consists of two steps: identification of deals carried on through the PE and determination of the PE remuneration. The first step is achieved by performing a functional and factual analysis and identifying the economically significant activities and responsibilities undertaken through the PE. The second step applies, by analogy, the transfer pricing (TP) rules. The difficulty in the allocation of profits to the PE results from the absence of legal contracts in transactions between the head-office and the PE (which from a legal point of view are treated as one enterprise) as opposed to transaction between associated enterprises (separate legal entities). Whereas transactions with third parties are identifiable, internal dealings are not. However, many MNEs use different internal systems of invoicing, thereby indicating these internal dealings. The aim of the AOA is to, first, test whether all internal transactions are indeed registered (which is 
probably not the case) and, second, to test these internal transactions to the arm's length principle.

According to Mr Nouel, the process of identification of internal dealings focuses on tax risk management. Despite that most transactions will be registered; the identification of all one-off activities remains a challenge. A particular difficulty arises in the context of PE which have been not treated as a PE from the beginning.

With the 2008 update, the functional and factual analysis starts with identifying significant peoples functions. The analysis continues with attribution of risks and attribution of economic ownership. The last step involved the attribution of free capital to support these risks and assets. In particular, the attribution of risks appears to be very important as risks follow functions and, in general, the higher the risk the higher the remuneration. In allocating the high risk functions (preferably in low-tax jurisdictions), not only tax rate, but also the business model, commercial issues and market conditions should be considered.

The allocation of tangible assets follows the place of usage as a pragmatic solution and otherwise the place where people functions related to these assets are performed. In case of intangible property the place where the people functions related to the management, creation or acquisition of the intangible are performed is used. However, also here difficulties may arise in case of acquisition of half-developed intangibles and further development or in case of categorisation of transactions, such as lease vs. service or sale vs. financial lease. Mr Nouel emphasized also the point that the allocation is only used to attribute profits (and costs) to the PE and provide double tax relief in country $R$; there is no allocation of notional profit in country $R$.

\subsection{Attribution of costs and expenses}

The presentation followed with the last topic: attribution of costs and expenses to a PE. Under the old Article 7(3) OECD MC, if read literally, one could conclude that the OECD MC allows deduction of all costs, even if disallowed under national law. However, this is not in accordance with the objective of the treaty, namely avoidance of double taxation. The Commentary clarified that expenses not deductible under domestic law, cannot be deducted based solely on Article 7(3) OECD MC. In addition, the old Article $7(3)$ does not really recognize the separate entity approach for the PE and therefore only the actual costs are deductible.

The allocation of debt and free capital to a PE appears to be extremely important. Under the pre-2010 guidance, interest on internal debt was not deductible. This approach corresponds to limitations by domestic legislation, treatment of the PEs not as a separate entity and, mainly, 
fear of abuse. The only exception was applied to financial institutions, because of the nature of business (banks borrow and lend money). In other cases it was possible to receive a reimbursement of deductible interest if debt was incurred for the purposes of the PE (for instance if the interest rate was $5 \%$ then costs were also $5 \%$ ). There is also no single view regarding the allocation of interest and two approaches are used the tracing approach and the fungibility approach.

Under the new commentaries on Article 7 OECD MC and the AOA, the assumption of a PE as a separate entity implies that the PE requires capital to supports its risks and assets. Various methods of attribution used by PE state may be acceptable, provided that they are consistent with the arm's length principle. The OECD recommends 3 methods as in agreement with the AOA: the capital allocation approach; the thin capitalization approach; and the safe harbour approach.

The 2010 OECD MC further embraces the separate entity approach and removes the limitations of old Article 7(3) OECD MC. The 2010 OECD $M C$ recognizes treasury functions and state that an enterprise must have enough treasury functions to allocate economic ownership of the money to the enterprise. Generally speaking, treasury functions will be allocated to a profit centre and include cash management, risk management and credit management.

\section{Concluding remarks}

On a personal note, the authors agree that the tax seminar has been valuable in preparation for the exam. Furthermore, the information provided by the speakers has given us new insights and a better understanding of double tax treaty abuse, the BEPS developments and Article 7 OECD MC. 